\title{
Evolution and Evaluation of Duplex Grain of As-cast 30Cr2Ni4MoV Steel during Heat Treatment
}

\author{
Xiuzhi ZHANG *, Zhilong LIU, Jiansheng LIU, Shue DANG \\ Taiyuan University of Sciences \& Technology, 66 Waliu Road, Taiyuan, 030024, P.R. China \\ cross ref http://dx.doi.org/10.5755/j01.ms.26.3.22102
}

Received 20 November 2018; accepted 08 February 2019

\begin{abstract}
As the main microstructure flaw of heavy forging, duplex grain (the grain size is non-uniform) may result in producing a reject. In this paper, the influences of heat treatment temperature and isothermal holding time on the duplex grains evolutions of as-cast $30 \mathrm{Cr} 2 \mathrm{Ni} 4 \mathrm{MoV}$ steel were studied using optical microscope and scanning electron microscope aided with XRD and EDS. It is shown that the globular austenite grains appear at $750{ }^{\circ} \mathrm{C}$ and the austenite grains in the regions rich in $\mathrm{C}, \mathrm{Cr}, \mathrm{Ni}$, and $\mathrm{Mo}$ are smaller than that in other regions. Duplex grains appear in the heating process. Moreover, in the isothermal heat treatment process, grains with different grain size number also developed at all of the temperatures performed in the study. But the distribution of the grains with different sizes cannot be evaluated precisely using proper method commonly used now. On the basis of analysis of the sizes of the duplex grains, a new approach for evaluating the level of the mixture of different size grains was proposed, the result obtained are consistent with the experimental results. The microstructure of $30 \mathrm{Cr} 2 \mathrm{Ni} 4 \mathrm{MoV}$ could be more uniform by increasing the temperature and extending the heat-preservation time.

Keywords: 30Cr2Ni4MoVsteel; duplex grain; duplex grain size; isothermal holding.
\end{abstract}

\section{INTRDUCTION}

$30 \mathrm{Cr} 2 \mathrm{Ni} 4 \mathrm{MoV}$ steel is widely used to manufacture steam turbine rotors and other heaving-forgings owing to the good balance of strength, toughness and wear resistance. The microstructure of $30 \mathrm{Cr} 2 \mathrm{Ni} 4 \mathrm{MoV}$ steel undergoes the phase transformation, recrystallization during forging and other hot working process. However, heavy forgings such as turbine rotors are high-technology products that require casting, forging and heat treatment. Inhomogeneity of the original ingot microstructure, thermodynamic factors, and deformation will result in the non-uniformity of the ingot microstructure after blank making. At the meanwhile, during the heating process of large steel workpieces, substantial temperature gradients will be induced between the surface and the core of the workpieces due to the finite heat conduction. Temperature gradients and local differences in time-temperature path at different positions in the workpieces may not only lead to thermal strains but also austenite grain size gradients because austenite grain growth is a highly temperaturedependent process [1]. The grain size and homogeneity of the original blank severely have influence on grains variation in the subsequent forging and other processing process and eventually have influence on the properties of the products [2-5]. Serious duplex grains will lead to producing a reject. Therefore, it should be paid more attention to the microstructure (especially grain size) evolution during the hot working process.

Many fundamental studies have been carried out on the microstructure of $30 \mathrm{Cr} 2 \mathrm{Ni} 4 \mathrm{Mo}$ steel. Chen investigated the evolution of $30 \mathrm{Cr} 2 \mathrm{Ni} 4 \mathrm{MoV}$ microstructure during recrystallization and austenitizing using cellular

\footnotetext{
* Corresponding author. Tel.: +86-351-2161126; fax: +86-351-2161126

E-mail address: zhangxiuzhi@tyust.edu.cn (X. Zhang)
}

automation method and experiments [6]. Constitutive modeling for high temperature flow behavior, dynamic recrystallization and metadynamic recrystallization of the steel was also established [7-9]. The as-cast microstructures, composition segregation, inclusions, and porosity of the steel were quantitatively analyzed in our previous study [10-11]. The evolution of the inclusions and porosity during forging process was also studied. Moreover, hot deformation behavior of as-cast 30Cr2Ni4MoV steel using processing maps was discussed by Zhou [12]. Grain boundary segregation and precipitation during the plastic deformation of $30 \mathrm{Cr} 2 \mathrm{Ni} 4 \mathrm{MoV}$ steel were studied [13].

However, most studies are only focused on the microstructure variation during the deformation process. Although metallurgical defect evolution has been studied in our previous, few investigations have been done on the influence of the original as-cast microstructure on the variation of the microstructure in subsequent heating processes before forging.

Therefore, this paper is focused on the variation of microstructures, especially grain size of as-cast large steel ingots during heating to different temperature and after isothermal holding for different time. A new evaluation methods for the duplex grain microstructure is explored.

\section{EXPERIMENTAL DETAILS}

\subsection{Samples preparation}

The material under study was cut from the part near to the riser of the ingot made of $30 \mathrm{Cr} 2 \mathrm{Ni} 4 \mathrm{MoV}$ and used to fabricate low-pressure rotors of $1000 \mathrm{MW}$ steam turbine. The test material was processed to specimens with dimensions of $15 \times 15 \times 15 \mathrm{~mm}$. These specimens were heated in a chamber-type electric furnace. 


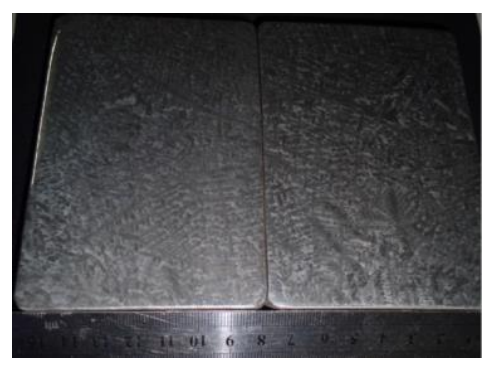

a

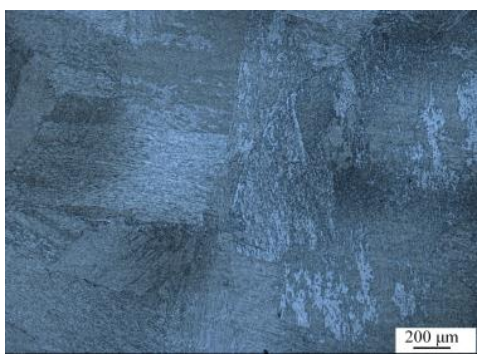

b

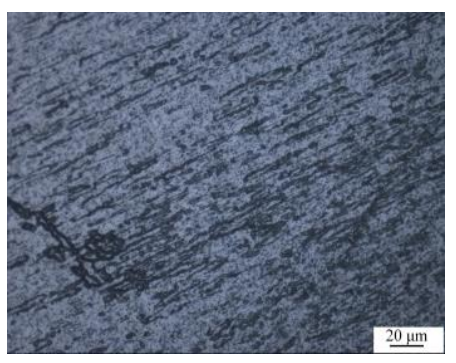

c

Fig. 1. Original microstructures of the as-cast $30 \mathrm{Cr} 2 \mathrm{Ni} 4 \mathrm{MoV}$ specimens: $\mathrm{a}$-dendrites; $\mathrm{b}$-non-directional dendrites; $\mathrm{c}$-the second phase

Table 1. Relationship of standard grain size number $\mathrm{N}$ vs. average interboundary $\mathrm{L}_{\mathrm{I}}$

\begin{tabular}{|c|c|c|c|c|c|c|c|}
\hline $\mathrm{L} / \mu \mathrm{m}$ & 320.0 & 269.1 & 226.3 & 190.3 & 160.0 & 134.5 & 113.1 \\
\hline $\mathrm{N}$ & 0 & 0.5 & 1 & 1.5 & 2 & 2.5 & 3 \\
\hline
\end{tabular}

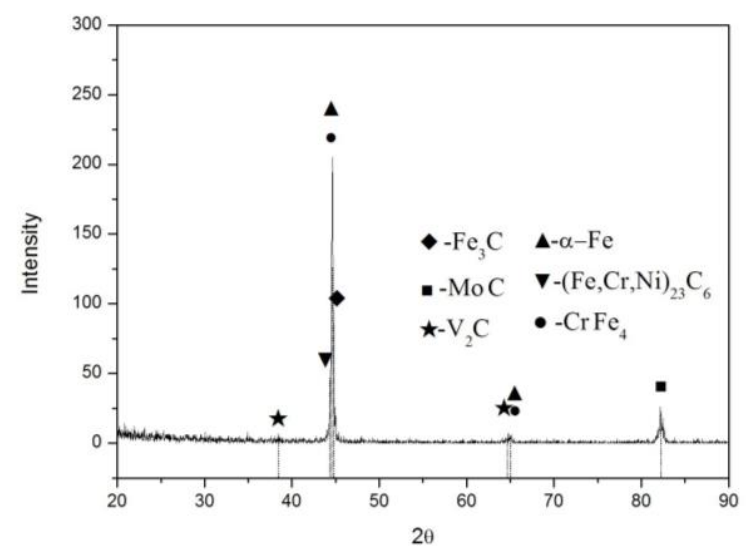

Fig. 2. XRD pattern of as-cast $30 \mathrm{Cr} 2 \mathrm{Ni} 4 \mathrm{MoV}$ sample

Two heating procedures were performed. In the first one, the specimens were continuously heated to $650{ }^{\circ} \mathrm{C}$, $700{ }^{\circ} \mathrm{C}, 750{ }^{\circ} \mathrm{C}, 800{ }^{\circ} \mathrm{C}, 850{ }^{\circ} \mathrm{C}$, and $950{ }^{\circ} \mathrm{C}$ at the rate of $15^{\circ} \mathrm{C} / \mathrm{s}$, and then quenched in water at room temperature. In the second one, specimens were heated to $1200{ }^{\circ} \mathrm{C}$ and $1250{ }^{\circ} \mathrm{C}$ and then kept at these two temperatures for 4,8 , 12,16 , or 20 hours. All the specimens were also quenched in water at room temperature after isothermal hold. After the heat treatment procedure, the specimens were ground, polished, and etched using 30:1 supersaturated picric acid, sodium dodecyl benzene sulfonate aqueous solution at $40{ }^{\circ} \mathrm{C}$. Metallographic features of the specimens were observed under a metallographic microscope and the S4800 scanning electron microscope made by Hitachi Company of Japan. X-Ray Diffraction (XRD) was used to identify the phases in the microstructure and the energydispersive X-ray spectroscope (EDS) system attached to scanning electron microscope was used to analyze the composition of phases.

\subsection{Grain size evaluated method}

Firstly, the secant method was applied to the specimen to randomly select the field of vision [14]. The maximum interboundary space $L i$ and the maximal vertical interboundary space $L_{i}{ }^{\prime}$ (vertical to the maximum interboundary space) were measured. The average $L_{I}$ of $L i$ and $L i^{\prime}$ was calculated, and the measured number of grains was determined from the given confidence interval and relative error $( \pm 5 \%)$ [15]. Secondly, by using the formula [15] $N=-6.643856 \times \log 10\left(L_{I}\right)-3.288$ to calculate the grain size $N, L_{I}$ in step (1) was converted to grain size accurate to the level of 0.5 . The standard grain size number is provided in Table 1. Subsequently, all grains were classified according to the grain size. Thirdly, the area $\mathrm{Si}$ of each grain is approximately equal to the oval area, which is the product of $L i$ and $L i^{\prime}$ multiplied by 0.785 (i.e., $\pi / 4)$ [16]. The total area $S_{I}$ of the grains in each grain size and the sum $S$ of the areas of all grains were calculated. Finally, the proportion of the area occupied by all grains in each grain size $I \%$ was determined: $I \%=S_{I} / S$. On the basis of $I \%$, the distribution curve of the grain size was plotted.

\section{RESULTS AND DISCUSSION}

\subsection{The original as-cast microstructures}

The original microstructure of samples cut from the as-cast $30 \mathrm{Cr} 2 \mathrm{Ni} 4 \mathrm{MoV}$ ingot is shown in Fig. 1. The microstructure of the as-cast steel had coarse dendrites (Fig. 1 a). Each dendrite showed nonuniform mass distribution without obvious directionality (Fig. 1 b). In Fig. $1 \mathrm{c}$, many aligned, linear, second-phase grains are distributed among the dendrite arms, grain boundary, and intergranular spaces. XRD result in Fig. 2 indicates that besides ferrite and $\mathrm{Fe}_{3} \mathrm{C}$, there are $(\mathrm{Fe}, \mathrm{Cr}, \mathrm{Ni})_{23} \mathrm{C}_{6}, \mathrm{MoC}$ and other carbides.

In order to know the composition of the second phase, the morphology of the specimens mentioned above was studied by scanning electron microscopy (SEM) with the function of EDS. The morphology of the specimen obtained by SEM is shown in Fig. 3. The presence of numerous, coarse second phases in the as-cast microstructures were confirmed. This is the result of the large steel billets undergoing a long period of high temperature during the cooling process. Because of the interfacial energy and solute segregation, the second phase of the alloy steel first precipitated to form a chainlike structure on the austenitic grain boundary and phase boundary [17-19]. Characteristics of the different regions (Fig. 3) and the corresponding EDS results in Table 2 suggest that the dark region in the microstructure (point 2) contained lower amounts of $\mathrm{C}, \mathrm{Cr}, \mathrm{Ni}$, and $\mathrm{Mo}$, while the second phase of brighter grains (points 1 and 3 ) contained more of such elements. On the basis of the results of XRD, 
it can be thought that the dark region is ferrite and the brighter grains may be the combination of $\mathrm{Fe}_{3} \mathrm{C}$, $(\mathrm{Fe}, \mathrm{Cr}, \mathrm{Ni})_{23} \mathrm{C}_{6}$ and $\mathrm{MoC}$.

\subsection{Variation of the microstructure of $30 \mathrm{Cr} 2 \mathrm{Ni} 4 \mathrm{MoV}$ in the heating process}

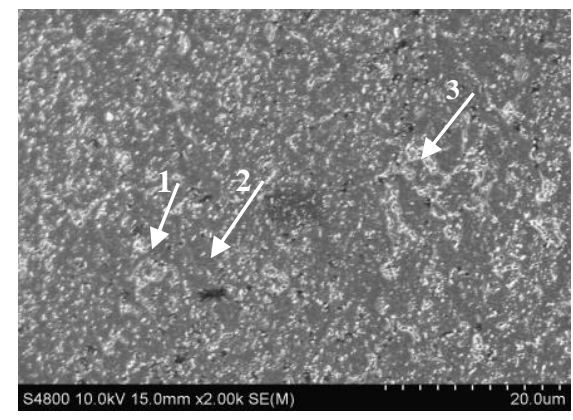

Fig. 3. SEM image of $30 \mathrm{Cr} 2 \mathrm{Ni} 4 \mathrm{MoV}$ specimens

Table 2. EDS results for the points shown in Fig. 3

\begin{tabular}{|c|c|c|c|c|c|}
\hline \multirow{2}{*}{$\begin{array}{c}\text { Analytical } \\
\text { point }\end{array}$} & \multicolumn{5}{|c|}{ Element content (wt.\%) } \\
\cline { 2 - 6 } & $\mathrm{C}$ & $\mathrm{Cr}$ & $\mathrm{Ni}$ & $\mathrm{Mo}$ & $\mathrm{Fe}$ \\
\hline 1 & 14.99 & 1.67 & 3.07 & 0.69 & 79.58 \\
\hline 2 & 12.25 & 1.43 & 2.69 & - & 83.63 \\
\hline 3 & 15.07 & 1.75 & 3.19 & 0.75 & 79.23 \\
\hline
\end{tabular}

The morphologies of the specimens in the heating process are shown in Fig. 4. It can be seen that after heating, particles with lower melting point in the original as-cast microstructures of the specimens remelt gradually as the temperature increased (Fig. $4 \mathrm{a}$ and b). At the same time, it is apparent in Fig. $4 \mathrm{c}$ that the globular austenite nuclei formed is not only on the original grain boundary or phase boundary, but also inside the grains. As the temperature increased to $800{ }^{\circ} \mathrm{C}$, austenite nuclei inside the original grains became larger and other new nuclei were formed. However, the nuclei cannot be found in the dark region (see Fig. 4 d), where the granular second phase of the as-cast microstructure is accumulated at the temperature. When the temperature is increased to $850{ }^{\circ} \mathrm{C}$ (Fig. 4 e), austenite grains newly formed replace the coarse dendrites of the original ingot, and the small austenite grains appear in the region of the second phase concentrated. The region becomes smaller gradually. In the subsequent heating process, the newly formed austenite grains become larger and the grain boundaries tend to be smooth (Fig. $4 \mathrm{f}$ ). However, the austenite grains in the dark region are markedly smaller than elsewhere.

According to reference [20], both the formation and the growth of globular austenite are diffuse types of phase transition. When heating the specimens above the eutectoid temperature $\left(\mathrm{Ac}_{1}\right)$, atoms on the boundary of ferrite and cementite in the original as-cast microstructures are disordered. So, nonuniform concentration of carbon, the high energies of the grain boundary and phase boundary provide favorable conditions for the required structural, composition, and energy fluctuation when the austenite nuclei are formed. Therefore, the austenite nuclei firstly appear on the grain boundary and on the phase boundary. However, according to reference [21], the elements such as $\mathrm{Cr}$, Mo, W, and $\mathrm{V}$, markedly decrease the diffusion velocity of carbon in the austenite by forming carbide. Therefore, the formation of austenite will be influenced by the type of elements contained in the alloy. As more elements such as $\mathrm{C}, \mathrm{Cr}, \mathrm{Ni}$, and $\mathrm{Mo}$ are present in the dark region than elsewhere as shown in Fig. $4 \mathrm{~d}$, the formation of austenite nuclei is delayed. As the temperature is increased enough and the condition for forming the austenite nuclei is satisfied, new austenite grains will be generated to replace the original as-cast microstructures in the region (see Fig. 4 e). Moreover, the grain growth tendency of austenite become smaller because there are many undissolved carbides in the accumulation area of the second phase in the as-cast microstructures. Therefore, the sizes of the grains are not uniform (Fig. $4 \mathrm{f}$ ).

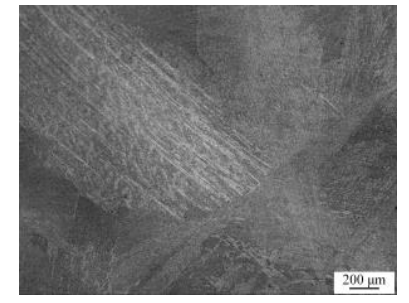

a

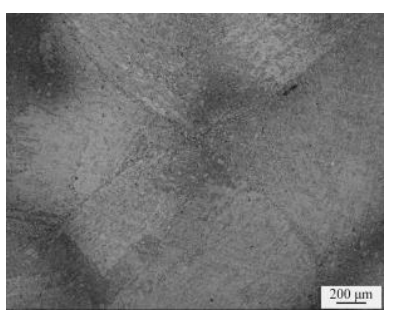

c

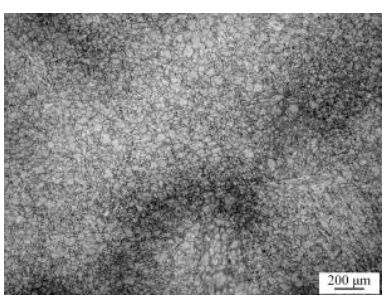

e

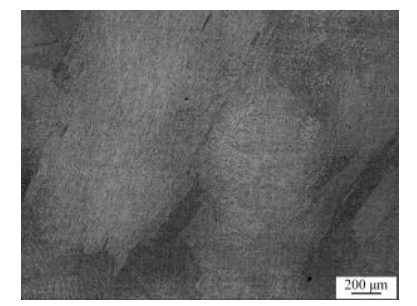

b

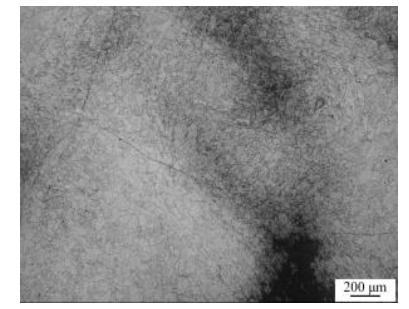

d

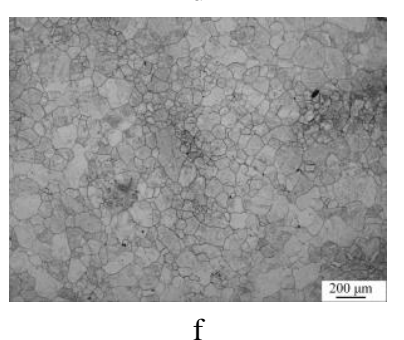

Fig. 4. Metallographic structure of the as-cast $30 \mathrm{Cr} 2 \mathrm{Ni} 4 \mathrm{MoV}$ ingot during heating to different temperature: $\mathrm{a}-650{ }^{\circ} \mathrm{C}$; $\mathrm{b}-700^{\circ} \mathrm{C} ; \mathrm{c} 750{ }^{\circ} \mathrm{C} ; \mathrm{d}-800{ }^{\circ} \mathrm{C}$; e $-850{ }^{\circ} \mathrm{C} ; \mathrm{f}-950{ }^{\circ} \mathrm{C}$

These phenomena show that because of the heterogeneous composition of the original as-cast ingot, different grain sizes (duplex grain) appear when the $30 \mathrm{Cr} 2 \mathrm{Ni} 4 \mathrm{MoV}$ ingot is heated.

\subsection{Grain size evolution of $30 \mathrm{Cr} 2 \mathrm{Ni} 4 \mathrm{MoV}$ during the isothermal holding}

Generally speaking, when samples are kept at the isothermal temperature, the grains of may grow and the grains size will become uniform. However, isothermal holding temperature and holding time depend on the material studied. For this reason the as-cast $30 \mathrm{Cr} 2 \mathrm{Ni} 4 \mathrm{MoV}$ specimens were heated to $1200{ }^{\circ} \mathrm{C}$ and $1250{ }^{\circ} \mathrm{C}$, respectively, and then subjected to isothermal temperature holding for different periods. Grain distributions upon heat preservation for different durations at each of two heating temperatures were obtained by using the method shown in 
2.2. The curve of area fraction of different grain sizes vs. grain size number at $1200{ }^{\circ} \mathrm{C}$ and $1250{ }^{\circ} \mathrm{C}$ are shown in Fig. 5 and Fig. 6.

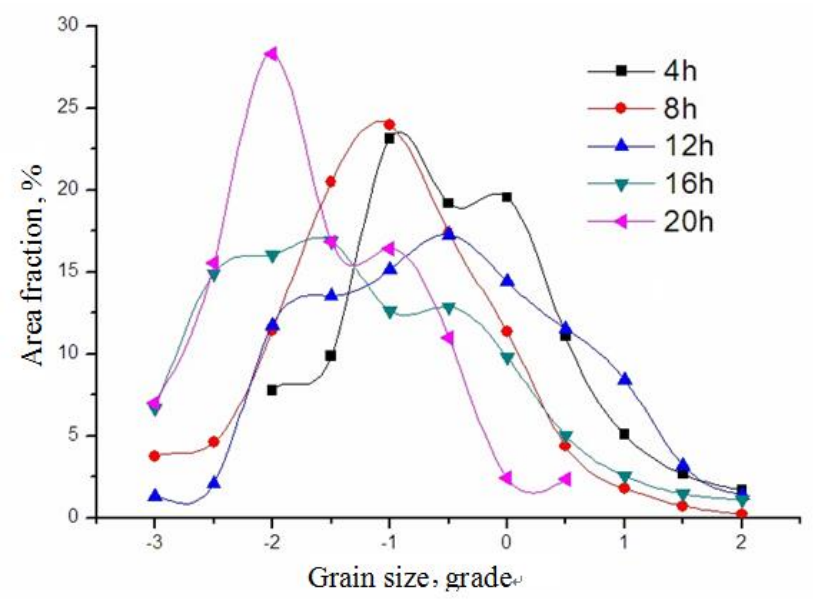

Fig. 5. Grain size distribution at $1200^{\circ} \mathrm{C}$

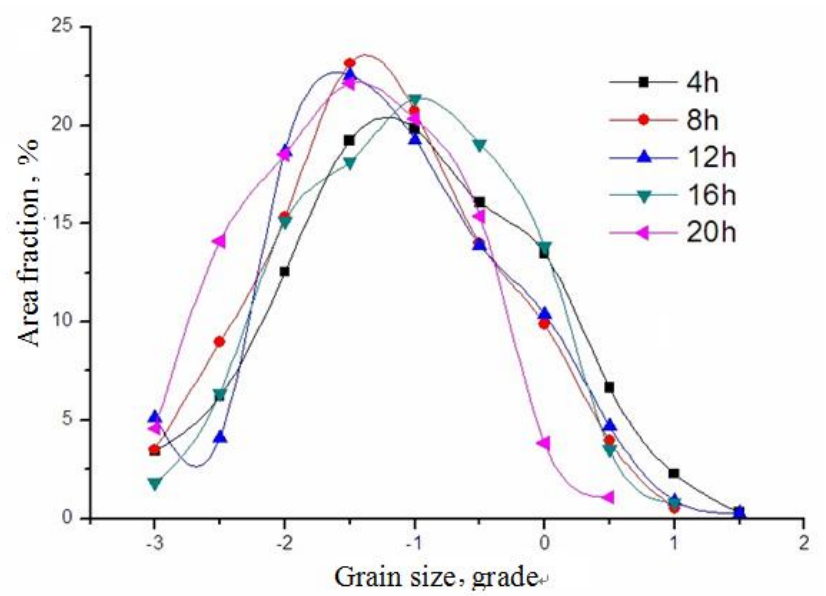

Fig. 6. Grain size distribution at $1250{ }^{\circ} \mathrm{C}$

From Fig. 5 it can be seen that there are two peaks in the curve of area fraction vs. grain size curve for holding 4 hours. The area fractions of the different grains at $1200^{\circ} \mathrm{C}$ for 4 hours mostly correspond to grain size number ranged in -1 to 0 . The area fraction occupied by grains with other grain size is lower than $10 \%$. At 8 hours, there is only one peak at grain size -1 . The grains are mostly at grain size number range of -2 to 0 . At 12 hours, the area fraction occupied by peak grain size, -0.5 , is near to that occupied by grains with size number of $-2,-1.5,-1,0,0.5$. Grain size is not uniform. Similar distributions are shown at 12 hours, and 16 hours where the grain size is distributed in the range of -2.5 to 0 . The grain is also multiple sized. At 20 hours, two peaks appear once more on the curve. However, the proportion of the area occupied by grains at peak grain size number of -2 is greater than that occupied by grains at the other peak grain size number of -1 . So the grains become much more uniform than before. Therefore, it can be seen that undergoing a nonuniform period of 12 hours to 16 hours, the grains size becomes less unevenly when the isothermal holding time reaches 20 hours. But the duplex grains still exist.

Fig. 6 indicates that there is one peak on each distribution curve of the area fraction occupied by grains with different grain sizes versus grain size at $1250{ }^{\circ} \mathrm{C}$. With an extended heat-preservation time, the grain sizes at the peak of the distribution curve vary very little and are concentrated near -1.5 . Therefore, the grain growth with an extension of heat-preservation time is not evident at $1250{ }^{\circ} \mathrm{C}$. However, the area occupied by grains sized -2 and 0 is near to that occupied by grains with grain size number of -1.5 . So, it can be concluded that the duplex grain microstructure also appears after isothermal holding at the temperature for different times.

\subsection{Evaluation of the duplex grain size number of 30Cr2Ni4MoV}

As mentioned above, the microstructure consisted of grains with different grain size numbers are obtained after both heating process and isothermal temperature holding.Undoubtedly, the duplex grain microstructure will increase the difficulty of forging and other subsequent processing processes to some extent. Some duplex grains can disappear during high temperature deformation. But serious mixed grains are difficult to be eliminated. So it is necessary to identify the level of the mixed grain size, i.e. duplex grain size number.

However, from the curves in Fig. 5 and Fig. 6, it is difficult to make clear the level of non uinformity. Thus, it is also difficult to identify the relationship between the non uinformity and the microstructure after following processing. Furthermore, according to the methods commonly used to evaluate mixed size grains $[15,20]$, the duplex grain sizes is divided into the ALA (as large as), wide-range, bimodal, cross-section, necklace, and band conditions. The wide-range condition, which is the condition of the duplex grain in this study, is characterized by not less than 5 levels difference between the maximum and the minimum grain size numbers with random distribution. According to reference [15], only the averages and two extreme values of the grain sizes can be obtained as shown in Table 3.

Table 3. Test results of duplex grains in the isothermal holding process of $30 \mathrm{Cr} 2 \mathrm{Ni} 4 \mathrm{MoV}$ steel

\begin{tabular}{|c|c|c|c|c|}
\hline $\begin{array}{c}\text { Holding } \\
\text { time, } \\
\text { hour }\end{array}$ & $\begin{array}{c}\text { Average } \\
\text { grain size } \\
\text { number, } \\
1200^{\circ} \mathrm{C}\end{array}$ & $\begin{array}{c}\text { Average grain } \\
\text { size } \\
\text { number, } 1250^{\circ} \mathrm{C}\end{array}$ & $\begin{array}{c}\text { Distribution } \\
\text { range of } \\
\text { grain size } \\
\text { number, } \\
1200^{\circ} \mathrm{C}\end{array}$ & $\begin{array}{c}\text { Distribution } \\
\text { range of } \\
\text { grain size } \\
\text { number, } \\
1250^{\circ} \mathrm{C}\end{array}$ \\
\hline 4 & -0.5 & -1 & -2 to 2 & -3 to 2 \\
\hline 8 & -1 & -1 & -3 to 2 & -3 to 2 \\
\hline 12 & -0.5 & -1 & -3 to 2 & -3 to 2 \\
\hline 16 & -0.5 & -1 & -3 to 2 & -3 to 2 \\
\hline 20 & -1.5 & -1 & -3 to 1 & -3 to 1 \\
\hline
\end{tabular}

From the result given in Table 3, although the distribution range of the grain sizes is described, the duplex grain size number and the distribution such as the area fraction of the duplex grains cannot be accurately determined. So, the influence of the mixed grains on the microstructure cannot be evaluated precisely. Therefore, it is necessary to propose a new method for the quantitative evaluation of duplex-grain size number.

On the basis of references [15,22], a new approach was proposed to evaluation the duplex grain size number. Here, the grain size number and area occupied were measured use the method shown in section 2.2. 
The grains whose difference in grain size number was assumed to be equal to the permitted duplex grain size number, at the same time grains taking up the largest area were assumed to be the dominant grains. The average grain sizes $N_{L}$ and $N s$ of all grains excluding the dominant grains were also calculated.

Firstly, when the proportions of the areas occupied by nondominant grains $\left(N_{L}\right.$ and $\left.N s\right)$ are both higher than $5 \%$, the duplex grain size number is $\Delta N=N s-N_{L}$, and the areaof the duplex grains is the sum of the two proportions. Secondly, when either $N_{L}$ or $N s$ is less than $5 \%$, the duplex grain size number is evaluated by considering grains with a larger area. The duplex grain size number is the maximum difference between the grain size of a single grain among the dominant grains and the size of the grains with the larger area. However, the area of the duplex grain is the sum of the areas occupied by nondominant grains $N_{L}$ and Ns. Finally, when $\mathrm{N}_{L}$ and $N s$ are both less than $5 \%$, the duplex grain of nondominant grains can be ignored.

Using the method described above, the variation of duplex grain size number with respect to isothermal holding time at temperatures of $1200{ }^{\circ} \mathrm{C}$ and $1250{ }^{\circ} \mathrm{C}$ were determined, as shown in Fig. 7 and Fig. 8.

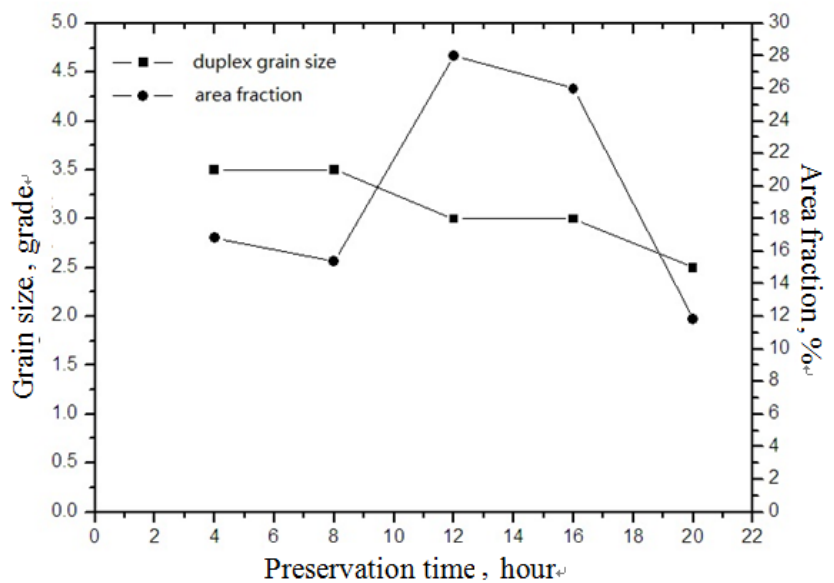

Fig. 7. Grain size and area fraction vs. heat preservation time at $1200^{\circ} \mathrm{C}$

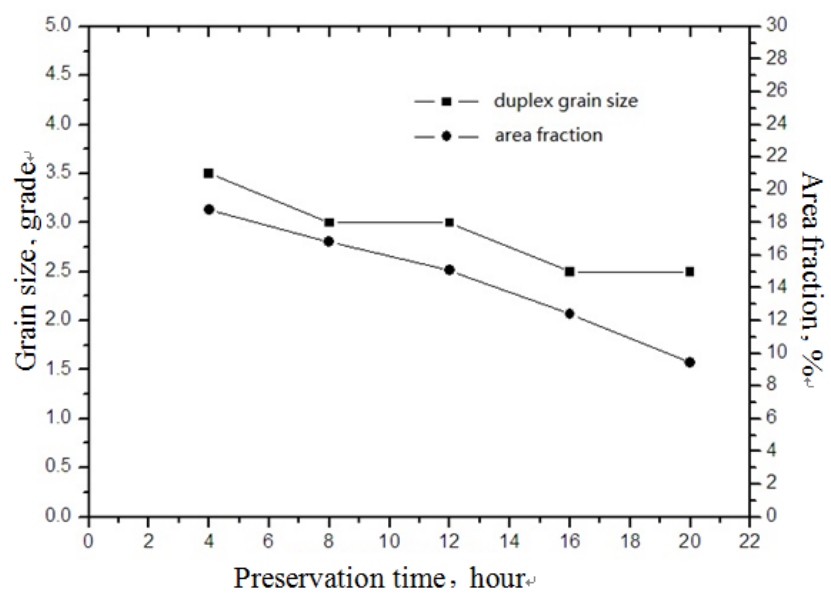

Fig. 8. Grain size and area fraction vs. heat preservation time at $1250^{\circ} \mathrm{C}$

It can be seen in Fig. 7 that the duplex grain size number decreases gradually with isothermal holding time at $1200{ }^{\circ} \mathrm{C}$. That is to say, the grain distribution becomes more evenly with the increasing holding time. However, the total area fraction occupied varies greatly. Although the duplex grain size numbers are the same when the temperature holding time are of 4 and 8 hours, the proportion of the area of the duplex grains at 8 hours was smaller than that at 4 hours. Hence, the distribution of the grains at 8 hours is more uniform than that at 4 hours. Moreover, with 12 hours and 16 hours holding time, the duplex grain size number becomes smaller with increasing holding time, but the area fraction increases markedly. Therefore, the distributions of the grains at 12 and 16 hours are much less uniform. When the isothermal holding time is 20 hours, the duplex grain size number and the area fraction decrease at the same time. Hence, the distribution of the grains is more uniform for this duration than other holding time.

Fig. 8 shows that the duplex grain size and the area fraction tend to decrease with holding time at $1250{ }^{\circ} \mathrm{C}$. Therefore, the distribution of the grains becomes increasingly uniform with an extension of preservation time at $1250{ }^{\circ} \mathrm{C}$. At a preservation time of 20 hours, the duplex grain size number is 2.5 and the area fraction is less than $10 \%$. Hence, the duplex grain is not included as the dominant grain and can be ignored. A comparison of Fig. 7 and Fig. 8 reveals that the distribution of the grains in $30 \mathrm{Cr} 2 \mathrm{Ni} 4 \mathrm{MoV}$ samples in the isothermal holding process may become more uniform upon an increase of the temperature and an extension of the isothermal holding time. The result meets well with the common law of heat treatment.

From the results shown in Fig. 7 and Fig. 8, it can be seen that the variation of duplex grain sizes coincide with the nonuniform variation of the grains shown in Figures 5 and 6 , correspondingly. The actual variation of the duplex grain sizes was determined accurately. Moreover, the size of single dominant grains was considered in the new method. Therefore, the method for characterizing the duplex grain sizes proposed in this study is reliable.

\section{CONCLUSIONS}

1. The as-cast $30 \mathrm{Cr} 2 \mathrm{Ni} 4 \mathrm{MoV}$ used to fabricate rotors presents the typical microstructure of coarse and irregular dendrites. There are second-phase grains rich in $\mathrm{C}, \mathrm{Cr}, \mathrm{Ni}$ and $\mathrm{Mo}$ in linear arrangement in the dendrite arms, grain boundaries, and intergranular spaces.

2. After the as-cast ingot specimen underwent heating, the duplex grains appear during grain growth because of the heterogeneous composition of the original ingot of $30 \mathrm{Cr} 2 \mathrm{Ni} 4 \mathrm{MoV}$ steel. The duplex grains are also developed during isothermal holdings at $1200{ }^{\circ} \mathrm{C}$ and $1250{ }^{\circ} \mathrm{C}$.

3. Evaluation of the duplex grain sizes upon hightemperature preservation of $30 \mathrm{Cr} 2 \mathrm{Ni} 4 \mathrm{MoV}$ steel reveals that the grain distribution in $30 \mathrm{Cr} 2 \mathrm{Ni} 4 \mathrm{MoV}$ could be more uniform by increasing the temperature and by extending isothermal holding time.

4. The new method proposed herewith can demonstrate the state of duplex grains more accurately. 


\section{Acknowledgements}

The paper was financially supported by the Chinese National Natural Science Fund (grant No. 51275330), the Taiyuan Science Project (grant No. 12022), China Scholarship Council Fund (grant No. 201608140160) and the Fund for Shanxi Key Subjects Construction.

\section{REFERENCES}

1. Sebastian, H., Besserer, H.B., Grydin, O., Milenin, A., Maier, H.J., Nurnberger, F. Holistic Consideration of Grain Growth Behavior of Tempering Steel 34CrNiMo6 during Heating Processes Journal of Material Processing Technology 229 2016: pp. 61-71.

https://doi.org/10.1016/j.jmatprotec.2015.09.015

2. Kisasöz, A., Karaaslan, A. Influence of Heat Treatment and Thermochemical Processes on the Properties of the Steel X38CrMoV 53 Materials Testing 54 2012: pp. 103-107. https://doi.org/10.3139/120.110301

3. Shneiderman, A.Sh. Prior Heat Treatment of Large Cr-NiMo-V Steel Forgings Metal Science Heat Treatment 26 1984: pp. $794-797$. https://doi.org/10.1007/BF00800219

4. Yu, W., Xu, S.X., Wang, B., Xie, B.S., Lei, L.Q., Zhang, Y. Direct Heat Treatment Process Experiment of 22CrNi3Mo Ultra High Strength Steel Transactions of Materials and Heat Treatment 36 2015: pp. 48-54. http://doi.org/10.13289/j.issn.1009-6264.2015.07.009

5. Huang, L.X., Hu, X., Yan, W., Xiao, F.R., Shan, Y.Y., Yang, K. Effect of Heat Treatment Processes on Microstructure and Mechanical Properties of Ton-scale China Low Activation Martensitic Steel Atomic Energy Science Technology 47 2013: pp. 412-416. http://doi.org/10.7538/yzk.2013.47.S1.0412

6. Chen, F., Cui, Z.S., Liu, J., Chen, W., Chen, S.J. Mesoscale Simulation of the High-temperature Austenitizing and Dynamic Recrystallization by Coupling a Cellular Automaton with a Topology Material Science \& Engineering A 527 2010: pp. 5539-5549. https://doi.org/10.1016/j.msea.2010.05.021

7. Chen, F., Ren, F.C., Cui, Z.S., Lai, X.M. Constitutive Modeling for Elevated Temperature Flow Behavior of $30 \mathrm{Cr} 2 \mathrm{Ni} 4 \mathrm{MoV}$ Rotor Steel Journal of Iron and Steel Research International 21 2014: pp. 521-526. https://doi.org/10.1016/S1006-706X(14)60081-9

8. Chen, F., Cui, Z.S., Chen, S.J. Recrystallization of 30Cr2Ni4MoV Ultra-super-critical Rotor Steel during Hot Deformation. Part I: Dynamic Recrystallization Materials Science \& Engineering A 528 2011: pp. 5073-5080. https://doi.org/10.1016/j.msea.2011.03.008

9. Chen, F., Cui, Z.S., Sui, D.S., Fu, B. Recrystallization of 30Cr2Ni4MoV Ultra-super-critical Rotor Steel during Hot Deformation. Part III: Metadynamic Recrystallization Mateials Science \& Engineering A 540 2012: pp. 46-54. https://doi.org/10.1016/j.msea.2012.01.061

10. An, H.P., Liu, J.S., $\quad$ Sun, H.Y., $\quad$ Ma, P., Jin, Y., Zheng, X.H., Tian, X.J., Guo, H.G. Anatomical Research on a Larger $2.25 \mathrm{Cr}-1 \mathrm{Mo}-0.25 \mathrm{~V}$ Steel Ingot The 12th National Plastic Engineering Academic Annual Meeting and the 4th Global Chinese Plastic Processing Technology Seminar 2011: pp. 256-258.

11. Xiang, W. Evolution of Main Metallurgical Defects in Large Ingot during Hot Forging. Taiyuan University of Science \& Technology thesis, Taiyuan, 2010: pp. 29-70.

12. Zhou, P., Ma, Q.X., Luo, J.B. Hot Deformation Behavior of As-Cast 30Cr2Ni4MoV Steel Using Processing Maps Metals 7 2017: pp. 50(1-12) https://doi.org/10.3390/met7020050

13. Zhao, W.L., Wang, D.P., Wang, H.D., Ma, S.C., Wang, Y.Y., Zhang, Y.Q. Grain Boundary Segregation and Precipitation during the Plastic Deformation of 30Cr2Ni4MoV Steel Materials Transaction 59 2018: pp. $822-828$. https://doi.org/10.2320/matertrans.M2017363

14. Lu, W.Z., Zhang, W.D. A New Method for Examining Duplex Grain Physics Examination and Testing 4 1990: pp. $48-50$.

http://doi.org/10.13228/j.boyuan.issn1001-0777.1990.04.015

15. GB/T 24177-2009. Standard test methods for characterizing duplex grain sizes.

16. ASTM E 930-2007. Standard test methods for estimating the largest grain observed in a metallographic section (ALA grain size)

17. Ma, F.J. Precipitation Behavior of the Second Phase and Microstructural Evolution of the Surface Layer of Microalloyed Slabs in Continuous Casting. Chongqing University thesis, Chongqing, 2010.

18. Sarazin, J.R., Hellawell, A. Channel formation in $\mathrm{Pb}-\mathrm{Sn}$, $\mathrm{Pb}-\mathrm{Sb}$, and $\mathrm{Pb}-\mathrm{Sn}-\mathrm{Sb}$ alloy ingots and comparison with the system $\mathrm{NH}_{4} \mathrm{CI}-\mathrm{H}_{2} \mathrm{O}$ Metallurgical Transaction A 19 1988: pp. $1861-1871$. https://doi.org/10.1007/BF02645156

19. Sample, A.K., Hellawell, A.The Mechanisms of Formation and Prevention of Channel Segregation during Alloy Solidification Metallurgical Transaction A 15 1984: pp. $2163-2173$. https://doi.org/10.1007/BF02647099

20. Cui, Z.Q. Metal Science \& Heat Treatment. Machinery Industry Press, Beijing, 2000: pp. 240-248.

21. Zhao, Z.K. Metal Science \& Heat Treatment Technology. National Defence Industry Press, Beijing, 2012: pp. 14-25.

22. ASTM E 1181-2002. Standard test methods for characterizing duplex grain sizes. 